\title{
Evaluation of endothelial dysfunction and its improvement after cardiac rehabilitation
}

Angela Cozma ${ }^{1}$, Adela-Viviana Sitar-Taut ${ }^{1}$, Adriana Fodor ${ }^{2}$, Monica Oltean ${ }^{3}$, Ioan-Alexandru Minciuna ${ }^{3}$, Iulia Breaban $^{4}$, Roxana Matuz ${ }^{3}$, Nicoleta Racataianu ${ }^{5}$, Gabriela Dogaru ${ }^{6}$, Olga Orăşan ${ }^{1}$

Corresponding author: Angela Cozma MD., PhD Lecturer angelacozma40@gmail.com,

\begin{abstract}
${ }^{1}$ Department of Internal Medicine, "Iuliu Haţieganu” University of Medicine and Pharmacy Cluj-Napoca, Romania ${ }^{2}$ Clinical Center of Diabetes, Nutrition, Metabolic diseases, "Iuliu Haţieganu" University of Medicine and Pharmacy ClujNapoca, Romania

${ }^{3}$ Department of Cardiology, "Iuliu Haţieganu” University of Medicine and Pharmacy Cluj-Napoca, Romania ${ }^{4}$ Department of Gastroenterology, "Iuliu Haţieganu" University of Medicine and Pharmacy Cluj-Napoca, Romania ${ }^{5}$ Department of Endocrinology, "Iuliu Haţieganu" University of Medicine and Pharmacy Cluj-Napoca, Romania ${ }^{6}$ Clinical Rehabilitation Hospital, "Iuliu Haţieganu” University of Medicine and Pharmacy "Iuliu Haţieganu” University of Medicine and Pharmacy Cluj-Napoca, Romania
\end{abstract}

All the authors contributed to the conception and design of the article. All of the authors approved the final version submitted for publication. Competing interests: none declared.

\begin{abstract}
Endothelial function is considered an independent predictor for risk of future cardiovascular events in cardiovascular and noncardiovascular patients. Given the prevalence of cardiovascular disease (CVD), preclinical detection may help modify atherosclerosis and prevent events. Although traditional cardiovascular risk factors relate to future CVD, the predictive value of these risk factors can be relatively limited. Contemporary scientific attention has focused on alternative direct measures of arterial function. Studies have provided unique insights into the pathophysiology of disease processes, the response to treatment and prognostic information that may be helpful in risk prediction. Peripheral measures of endothelial function are now established surrogate markers of vascular risk and have become important markers for clinical research. Cardiac rehabilitation (CR) is of critical importance in the secondary prevention of cardiovascular disease. It has been reported that CR was negatively related to reinfarction, cardiac morbidity and all-cause mortality. The beneficial influence of cardiac rehabilitation on endothelial dysfunction has been demonstrated in many studies, but the the mechanisms by which exercise improves endothelial function are not fully clarified.
\end{abstract}

Key words: endothelial dysfunction, cardiac rehabilition, subclinical atherosclerosis,

\section{Introduction}

The endothelium plays an important role in maintaining vascular homeostasis and regulating blood vessel function. Endothelial function is considered an independent predictor for

risk of future cardiovascular events in cardiovascular and noncardiovascular patients[1]. Given the prevalence of cardiovascular disease (CVD), early detection is crucial. Although traditional cardiovascular risk factors relate to future CVD, the predictive value of these risk factors can be relatively limited. Contemporary scientific attention has focused on alternative direct measures of arterial function[2].

Cardiac rehabilitation (CR) is critically important in secondary prevention of cardiovascular disease. CR has been reported to be negatively correlated with reinfarction, cardiac morbidity and all-cause mortality. Many studies have demonstrated the beneficial effect of cardiac rehabilitation on endothelial dysfunction, but the mechanisms by which exercise improves endothelial function are not completely understood.

Vascular endothelium is a monocellular structure that lines the entire vascular tree. It is not just an anatomical barrier between circulating blood and vascular muscle cells, but it plays an essential role in a multitude of fundamental physiological pathways: hemostasis, transport of metabolites between the blood and tissues, angiogenesis, vascular damage repair, muscle tone control. The main function of healthy vascular endothelium is vasodilation. Nitric oxide is the most important vasodilator substance produced by endothelial cells. Initially, it was termed EDRF (endothelium-derived relaxing factor) by Furchgott and Zawadzki, then Moncada [3] and Ignarro identified this substance as being NO, a gaseous free radical with a role in mediating many vascular smooth muscle relaxants such as bradykinin, histamine, serotonin, acetylcholine, and ATP. So, nitric oxide can be considered an endogenous nitric derivative, which is generated by vascular endothelium and induces 
localized smooth muscle cell relaxation and platelet aggregation inhibition[4].The endothelium can mediate vascular tone by other pathways: through the endothelium-derived hyperpolarizing factor [5], which is important when NO bioavailability is reduced, compensating NO-mediated vasodilation, particularly in the microcirculation [6]. Prostacyclin, another endothelium-derived vasodilator substance, plays a less important role in maintaining vascular tone.

Endothelial dysfunction (ED) is defined as a reduction in the bioavailability of vasodilators, particularly NO, and an increase of vasoconstrictors. Along with its structural and functional consequences, arterial remodeling and stiffness represents the link between cardiovascular risk factors and the initiation of atherosclerosis, as well as the main element causing its complication.

When assessing endothelial function, the following are taken into account: the choice of the invasive/non-invasive method,

the coronary/peripheral/microcirculation level, advantages/disadvantages, clinical implications and prognosis.

Endothelial dysfunction in coronary arteries was first described by Ludmer et al. in 1986 [7]. Since then, invasive assessment of coronary endothelial function by angiography or intracoronary ultrasound has become the gold standard. Over the past decades, less invasive or non-invasive techniques for the evaluation of endothelial function have been developed, based on the fact that endothelial dysfunction is a systemic change that involves the entire vascular bed [8]. Endothelial dysfunction is assessed by:

a) invasive or non-invasive imaging, associated with various physiological or pharmacological stimuli;

b) determination of biochemical markers; [9-11]

c) determination of genetic markers (Table 1)

These techniques are based on the measurement of endothelial vasodilator response to the administration of different substances that induce NO release (acetylcholine, bradykinin). Endotheliumdependent vasodilation can be thus assessed by invasive or non-invasive imaging techniques, applied at central or peripheral arterial level. In addition to these, biological and genetic markers correlated with endothelial dysfunction can be determined [12]
Over the past years, various methods for the assessment of endothelial function have been developed. Thus, arterial stiffness parameters, including pulse wave velocity and arterial distensibility, have been used as endothelial dysfunction measurement methods. The latest candidates for non-invasive testing of endothelial function are [13]: PWA=pulse wave analysis (modification of the augmentation index); $\mathrm{PCA}=$ pulse contour analysis (modification of the reflection index); PAT=pulse amplitude tonometry (modification of pulse amplitude). For the assessment of microvascular ED, the RH-PAT (reactive hyperemia pulse amplitude tonometry) method was described by Hamburg et al. [14]

In 2007, Deanfield et al.[13] mentioned that the ideal method for the assessment of endothelial function should be safe, non-invasive, reproducible, repeatable, inexpensive and standardized. No test meets all of these requirements, but FMD meets most of them. The table 2 and 3 presents all these characteristics.

Imaging methods for the assessment of endothelial function

\section{Invasive techniques}

Applied to coronary arteries

Quantitative coronary angiography

Quantitative coronary angiography assesses vascular diameter changes in response to intracoronary infusion of vasoactive agents. This is the method of choice for direct evaluation of endothelial function in coronary arteries, allowing to quantify the relationship between dose and response to administration of endothelial agonists or antagonists, as well as to establish basal endothelial function by administration of $\mathrm{NO}$ synthase inhibitors. In the presence of an intact functional endothelium, the administration of acetylcholine or other vasodilator analogues - bradykinin, substance $\mathrm{P}$ - induces coronary artery dilation, through a NO-mediated vasodilator response. In patients with endothelial dysfunction, this response is significantly diminished, or paradoxical vasoconstriction may occur through direct action of acetylcholine on muscarinic receptors in smooth muscle cells [16].

Intracoronary ultrasound

By means of a transducer placed at the tip of a proximal anterior interventricular artery catheter, intracoronary flow velocity and the amplitude of vasodilator response to infusion of progressively 
increasing acetylcholine doses (e.g., 1, 3, 10 and 30 $\mu \mathrm{g} / \mathrm{min})$ are recorded by spectral Doppler. Endothelial function is evaluated by dose-vasodilator response curve analysis [17]. Finally, vasodilator response to acetylcholine or other agonists (NOdependent response) is compared to the response to nitroglycerin administration (NO-independent response). This method has the disadvantage of being invasive and expensive, and cannot be used on a wide scale as a screening method for early atherosclerosis.

Applied to peripheral arteries

There are studies that demonstrate the correlation between endothelial function in coronary arteries and endothelial function in peripheral arteries (e.g., the brachial artery)[18]. Thus, vasoactive agent infusion can also be applied to peripheral arteries, the method being more accessible and involving fewer risks than that applied to coronary arteries. The function of resistance vessels in the forearm is assessed by strain-gauge plethysmography. This method measures the changes in forearm blood flow (FBF) in response to direct infusion of vasoactive agents.

Although this technique is relatively easy to use and has satisfactory reproducibility, with a 5-8\% variation of results when repeating it at various time intervals [19], it remains an invasive method that can potentially affect the median nerve or the brachial artery.

\section{Non-invasive techniques}

Applied to coronary arteries

Positron emission tomography (PET) and magnetic resonance imaging (MRI)

There are relatively few literature data reporting the use of these imaging techniques for the assessment of endothelial function in coronary arteries. The principle consists of evaluating coronary perfusion in response to the application of various vasoactive stimuli using the above mentioned methods [20].

Applied to peripheral arteries

High-resolution vascular ultrasound assessment of flow-mediated vasodilation (FMD)

High-resolution vascular ultrasound is currently the method recommended and validated by guidelines for the study of early changes in arterial physiology, i.e., vasomotor tone or vascular reactivity. The normal response of vascular endothelium to various local physical or chemical stimuli consists of an increase of shear stress and, implicitly, of blood flow, translating into vasodilation. This process is termed flow-mediated vasodilation (FMD) and reflects the endothelial capacity to produce NO [21] .

The role of NO in flow-mediated vasodilation was demonstrated by the administration of a $\mathrm{NO}$ synthase inhibitor such as L-NMMA (Nmonomethyl-L-arginine). Its infusion in the brachial artery leads to an $85-95 \%$ decrease of FMD, showing that NO is the main regulator of this process. Other substances released from the endothelium, such as prostacyclins or endothelium-derived hyperpolarizing factor (EDHF), seem to contribute to a smaller extent to FMD. Bellien et al [22] (also demonstrated a role for endothelium-derived hyperpolarizing factor (EDHF) during a sustained shear stress stimulus (ie, hand warming) because this vasodilator response is attenuated to a greater extent when EDHF inhibition is performed in combination with NO blockade compared with selective inhibition. This supports the presence of cross-talk between NO and EDHF and suggests a role for EDHF in the FMD response.

Many studies show that FMD depends on the procedure used. Thus, since the initial description given by Celermanjer in 1992 [23] the method has undergone a lot of changes. While the guidelines published by Coretti [24] in 2002 do not accurately indicate the position of the sphygmomanometer cuff, recent studies have shown that the place of the cuff is extremely important to obtain a NO-dependent effect [25].

Another parameter, flow-mediated vasoconstriction (FMC), described by Gori et al. [26], is another indicator of endothelial function and mainly reflects the basal state of the endothelium, being mediated by other vasodilator factors released from the endothelium: EDHF and prostacyclin.

This method for the evaluation of endothelial function includes: preparation of the patient, image acquisition, and assessment of endotheliumdependent as well as endothelium-independent FMD. Many factors, such as environmental temperature, diet, various medications or sympathetic stimuli, influence vascular reactivity. This is why adequate preparation of the patient is a compulsory stage for obtaining correct results. A period of at least 8-12 hours fasting, as well as cessation of smoking at least 4-6 hours prior to examination and discontinuation of 
vasoactive medication 12 hours before examination are required. The patient must be examined at rest, in dorsal decubitus, with the arm to be examined in a comfortable position, in a quiet room with constant temperature, and these conditions should be maintained for at least 10 minutes. Blood pressure and ventricular rate should be continuously monitored.

Early studies were difficult to interpret because of the lack of a standardized procedure and these were addressed by several guideline recommendations [24,27]. Highly standardized labs will now employ rigorous protocols that may include a) an arm fixation device, b) B mode edge detection tracking, c) off-line analysis, d) determination of peak dilation as opposed to dilation at 60 seconds, and e) discontinuation of vasoactive drugs. With these measures in place test test co-efficient of variation should be in the $10-15 \%$ range. Baseline responses in healthy population with a lower arm cuff position will generally be 5-8\% depending on the baseline brachial artery diameter, which is an important determinant of response [28].

Assessment of endothelium-dependent vasodilation

To obtain blood flow stimulation in the brachial artery, a sphygmomanometer cuff is placed on the antecubital fossa or on the forearm. Recent studies [29-31] have shown that the tensiometer cuff is placed $5 \mathrm{~cm}$ below the medial epicondyle and the probe is fixed using a stereotactic arm with a micrometer screw.

Endothelial dysfunction, assessed by impaired FMD, has been extensively associated with most of the established and emerging $\mathrm{CV}$ risk factors (e.g. dyslipidaemia, hypertension, smoking, diabetes mellitus, family history of premature atherosclerosis, elevated plasma homocysteine), as well as with the presence and extent of structural arterial disease and prevalent $\mathrm{CV}$ disease. Assessment of endothelial dysfunction using FMD appears to complement other imaging endpoints of structural arterial disease burden, probably preceding their occurrence [32].

After recording of the mean basal velocity, the sphygmomanometer cuff is inflated above the systolic blood pressure value (usually by more than $50 \mathrm{mmHg}$ ) for 5 minutes, in order to induce brachial artery ischemia and, implicitly, dilation of downstream resistance vessels through a selfregulating mechanism. It has been found that brachial artery dilation increases proportionally to the duration of ischemia during the first 30 seconds -5 minutes, and subsequently remains constant. Thus, the 5 minute duration of ischemia, the best tolerated, is also the most frequently used [24]. Sudden cuff deflation leads to an increase of brachial artery blood flow (active hyperemia) and shear stress at this level, with consecutive brachial artery dilation. Maximum blood flow velocity is measured by pulsed wave Doppler within 15 seconds from cuff deflation, while maximal brachial artery diameter is determined 45-60 seconds after hyperemia[24]. It is important to measure the brachial artery diameter in the same period of the cardiac cycle in order to avoid variations caused by arterial compliance. Thus, FMD is defined as the percent variation of the basal brachial artery diameter 60 seconds after hyperemia. However, the American guidelines for the assessment of endothelial function recommend to measure the basal diameter, its percent variation, and also its absolute variation. Additional information can be provided by evaluating the time required for maximal vasodilation, the duration of vasodilator response, and the area under the curve of diameter - time elapsed from the deflation of the sphygmomanometer cuff.

Flow-mediated vasoconstriction (FMC)

Gori and Parker proposed that an assessment of basal endothelial function could be obtained by evaluating the decrease in brachial artery diameter following cuff occlusion compared with the resting baseline [26].The decrease in diameter would be related to the basal shear stress mediated dilation that is removed with cuff occlusion. Greater basal endothelial function would be reflected by a greater FMC. Gori reported that FMC was attenuated in response to risk factors, acute cigarette smoking, was not correlated with FMD and was not NO dependent. Numerous other studies by the same group have provided further information about the potential utility of this metric. [33-35]. Further studies evaluating the prognostic utility of FMC is required.

Assessment of endothelium-independent vasodilation

Concomitantly with the evaluation of FMD, the study of endothelial function includes the testing of endothelium-independent vasodilation to dissociate the per se effect of vascular remodeling on local arterial function. Thus, after a rest period of at least 10 minutes required to restore the basal flow, a single dose of $0.4 \mathrm{mg}$ nitroglycerin spray or sublingual tablet (exogenous NO donor) is administered. The brachial 
artery lumen diameter is assessed 4 minutes after NTG administration, when maximal vasodilation is reached. Determining vasodilator response to progressively increasing NTG doses provides additional information regarding changes in the smooth muscle layer function and arterial compliance, factors that can influence FMD.

\section{The clinical implications}

The continuously developing ultrasound technique for the assessment of flow-mediated vasodilation (FMD) evaluates endothelial function with a high accuracy. Although the method is highly operator-dependent and requires good patient compliance, it has the advantages of being noninvasive, safe, easy and rapid to perform, highly reproducible (in specialized laboratories, the variability coefficient is $3-4 \%$ in the short-term as well as in the long-term)[36]. Shimbo et al. report a $1.3 \%$ intra-observer variability for FMD [37]. In the same study, FMD is associated with an increase of cardiovascular events. The clinical implications of the method are extremely important, many studies conducted over the past years suggesting the fact that endothelial dysfunction is a preclinical marker for atherosclerotic disease, as well as for the rate of subsequent cardiovascular events [38]. In the NOMAS study [39], the authors defined endothelial dysfunction as a decrease of FMD to less than $8.4 \%$. Recently, FMD proved to be a predictor for cardiovascular events in 2791 elderly subjects in the Cardiovascular Health Study[40].Many studies have shown an alteration of FMD in metabolic syndrome [41].

Endothelial dysfunction - arterial stiffness parameters

Non-invasive methods for the determination of arterial stiffness and wave reflection have been recently developed and used as methods for the assessment of endothelial function [13].

PWV results from the analysis of the pulse wave generated by each ventricular ejection and propagated along the arterial tree. The propagation of this wave is determined by the elastic properties and the thickness of the vessel, as well as by blood flow density. The lower the vessel distensibility, the higher the wave propagation velocity is. Consequently, PWV is correlated with arterial stiffness and, at the same time, is an important indicator for the evaluation of atherosclerosis [42]. The measurement of PWV is an easy, non-invasive, highly reproducible method that reflects arterial stiffness and is currently considered an independent indicator of cardiovascular mortality. Thus, studies show that cardiovascular mortality in hypertensive patients with a PWV value higher than $14 \mathrm{~m} / \mathrm{s}$ is significantly increased compared to the control group (odd ratio 7.1\%)[43]. At the same time, new data show a strong correlation between non-invasive estimation of arterial stiffness by PWV and endothelial dysfunction assessment by FMD in the brachial artery of patients at high risk for atherosclerosis (correlation coefficient $\mathrm{r}=-0.32, \mathrm{p}=0.001)$ [42]. Ramsey et al. demonstrated that the distensibility of conductance arteries is increased by acetylcholine in healthy subjects, but remains unchanged in subjects with cardiac failure, which involves endothelial dysfunction. Endothelium-independent stimuli (adenosine and nitroglycerin) induce an increase of arterial distensibility, which is preserved in patients with heart failure. PWV during exercise-induced hyperemia is low in the presence of L-NMMA and in patients with chronic heart failure, an effect mediated by NO [44]. Other studies have shown that PWV can be altered by endothelium-dependent vascular tone changes mediated by NO [45].

Naka et al. propose a new method for determining endothelial dysfunction: the measurement of the acute response of pulse wave velocity to the increase of blood flow in hyperemia, PWV variation exceeding arterial diameter variation during hyperemia, 14\% vs 9\% [46]. A number of noninvasive techniques have been recently developed to assess the vascular biology of peripheral circulation[13]. These techniques are based on the capacity of beta-2 agonists to reduce arterial stiffness in a NO-dependent manner, without a significant change of blood pressure[47]. The modification of arterial stiffness can be evaluated by pulse wave analysis (PWA) using arterial tonometry or by pulse contour analysis (PCA) using digital photoplethysmography[47]. The following noninvasive methods for the assessment of endothelial function are currently accepted: PWA=pulse wave analysis (modification of the augmentation index); PCA=pulse contour analysis (modification of the reflection index); PAT=pulse amplitude tonometry (modification of pulse amplitude) [13]. Thus, pulse wave analysis in the radial artery is used as a method for the evaluation of endothelial function [48].Another method for the assessment of 
endothelial function is the use of beta- 2 adrenergic agents followed by pulse wave analysis or digital pulse analysis. The response to salbutamol is subsequently compared with the response to nitroglycerin. It was observed that reduction of the augmentation index after salbutamol administration is altered in patients with diabetes mellitus, hypercholesterolemia [48] and ischemic cardiopathy [49]. Wilkinson et al. also demonstrated that the response to salbutamol in patients with hypercholesterolemia is very well correlated with the response to acetylcholine in the forearm [48]. Hamburg et al. conducted a PAT analysis in 1957 patients, demonstrating a negative correlation between PAT and certain cardiovascular risk factors [49].

Given the novelty of the technique, relatively few clinical studies have employed pulse wave analysis (PWA) to assess endothelial function. However, impaired endothelium-dependent responses have been observed in conditions traditionally associated with endothelial dysfunction, including diabetes, hypercholesterolemia, coronary artery disease, peripheral vascular disease, and rheumatoid arthritis. An inverse correlation between terbutaline response and Framingham risk score has been reported, along with a stronger correlation between individual risk factors and endothelial function assessed with PWA compared to FMD $[29,48,49]$.

\section{Strain-gauge plethysmography}

Another non-invasive modality to assess endothelial function is by determining the change in forearm blood flow (FBF) during reactive hyperemia. This technique evaluates the percent variation in blood flow from baseline to peak during reactive hyperemia determined by 5 minutes of forearm ischemia, using strain-gauge plethysmography. FBF is measured with a strain-gauge device placed around the maximum diameter of the forearm and connected to a plethysmograph. A cuff positioned on the arm is inflated to $40 \mathrm{mmHg}$ for 7 seconds every 15 seconds to block the arm venous flow. The FBF recording signal is transmitted to a computer at the periphery. FBF is expressed in $\mathrm{ml} / 100 \mathrm{ml}$ forearm tissue per minute and is estimated as the mean of 10 measurements made by 2 independent examiners (intra-observation variation $<4 \%$ ) [50]. Another cuff placed on the forearm is inflated to $50 \mathrm{mmHg}$ above systolic pressure for 5 minutes to induce ischemia.
FBF is measured every 15 seconds after cuff deflation and the time-flow curve is drawn. Through this technique, endothelial function is assessed using the following parameters: maximum blood flow during reactive hyperemia, percent variation of basal and maximal flow, as well as the analysis of the area under the time-flow curve. This reflects the overall vasodilator capacity of resistance vessels and is considered an indirect indicator of endothelial function [51]. Another vasodilator stimulus that can be used as an alternative to reactive hyperemia is the local heating test or the cold pressor test (CPT) [52]. This induces catecholamine release and stimulation of endothelium-dependent vasodilation in the brachial artery, by increasing shear stress and implicitly, the release of $\mathrm{NO}$ and/or EDHF. CPT consists of immersing a hand in cold water for 2 minutes and determining vasodilator response by various methods: assessment of coronary blood flow by angiography, FBF by strain-gauge plethysmography, or percent variation in the brachial artery diameter by high-resolution ultrasound.

Microvascular endothelial function

Microcirculation endothelial function is generally difficult to assess. Literature data present results obtained in vitro, in response to agonists stimulating endothelial vasodilator receptors (acetylcholine, bradykinin, substance P). Small resistance vessels are mounted on a micromyograph. Many studies have reported an altered vasodilator response in animal hypertension models. It is not yet clearly established whether endothelial function in subcutaneous microvessels reflects endothelial function at other levels. Many studies shows a correlation between microvascular endothelial function and brachial artery endothelial function. [4952]. Dhindsa, in a study published in 2008, evidenced the relationship between microvascular and macrovascular reactivity evaluation methods, demonstrating the absence of a correlation between FMD and local pulse wave velocity, measured between the brachial and radial artery [53].

Digital laser Doppler/iontophoresis

This technique allows the non-invasive assessment of microvascular endothelial function. Reactive response to local application of endothelium-dependent vasodilators by iontophoresis provides useful information regarding this vascular bed. 
RH-PAT (reactive hyperemia pulse amplitude tonometry) has been proposed [49] as a method to assess microvascular endothelial dysfunction. Measuring RH-PAT allows to estimate digital arterial pulse volume at rest and under increased shear stress conditions resulting in the release of nitric oxide and other mediators.

The measurement of digital pulse volume amplitude (PVA) during reactive hyperemia (PVA$\mathrm{RH}$ ) has been proposed as an easy and useful method to assess endothelial dysfunction [54] and nitric oxide bioavailability. In this study, the central role of NO in increasing PVA during reactive hyperemia was shown. Another study performed in 2000 patients [12] evidenced the presence of a correlation between the digital pulse amplitude response to hyperemia and cardiovascular risk factors.

Bonetti [55] showed that reduction of digital pulse amplitude response to hyperemia is a predictor of coronary endothelial dysfunction.

Noninvasive, finger probe-based methods exist for endothelial function assessment: digital thermal monitoring (DTM), digital volume photoplethysmography (DVP) and, the most widely used, endothelial peripheral arterial tonometry (EndoPAT). DTM is a technique that shares the same pathophysiological background with FMD using temperature as a surrogate marker of blood flow; nevertheless few studies with small sample sizes have been published to date [56,57] Similarly, DVP has been used for endothelial function assessment on top of its use for pulse wave analysis [58]. The pathophysiological background of EndoPAT is similar to that of brachial FMD, since both assess endothelial function. Nevertheless, several studies have reported low to moderate correlation between the two methods, suggesting that FMD and EndoPAT provide distinct information regarding vascular function [59-61].

Determination of biological markers correlated with endothelial dysfunction

Atherosclerosis is currently regarded as a dynamic and progressive process, determined by the combination of endothelial dysfunction, inflammation and thrombosis. Endothelial dysfunction occurs before the structural development of atherosclerosis and is an independent predictive factor for future cardiovascular events. Over the past years, a number of biohumoral inflammation and platelet activation markers have emerged, by which endothelial function can be assessed and the cardiovascular risk profile of patients can be completed. Of these, we mention C-reactive protein (CRP), interleukin 6, tumor necrosis factor, a series of adhesion molecules (VCAM-1, ICAM, P-selectin), CD-40 ligand, lipoxygenase-1, microalbumin $[11,12]$. Recent studies show that high-sensitivity Creactive protein (hs-CRP) represents not only an inflammatory marker of atherosclerosis, but also a mediator of disease progression. It contributes to the development and progression of atheroma plaque by promoting inflammation and thrombogenesis, as well as by affecting endothelial function. CRP has been demonstrated to diminish NO synthase function and implicitly, endothelial NO production, with an increase in the release of vasoconstrictor substances (endothelin 1). At the same time, it stimulates endothelial cell apoptosis and affects the survival and differentiation rate of endothelial progenitor cells. Thus, CRP can be regarded as an indirect but important marker of endothelial function [62]. Determining biohumoral markers has the advantage of being an easy-to-use, inexpensive, highly reproducible method, but establishing a relationship between these markers, endothelial dysfunction and their prognostic value for cardiovascular events requires further studies [63-65].

Genetic markers correlated with endothelial dysfunction

Currently, genes such as those of angiotensin converting enzyme, endothelin converting enzyme 1, endothelial NO synthase, superoxide dismutase, some proinflammatory mediators are investigated. The study of the molecular basis of endothelial dysfunction by determination of genetic markers could be a particularly useful method in the future. A number of genes involved in endothelial function have been described. Current candidate genes include: angiotensin I converting enzyme (ACE), preproendothelin (ET)-1, endothelin converting enzyme 1 (ECE-1), endothelin B receptor, eNOS [66], NF-kB, ICAM-1, VCAM-1, E-selectin, von Willebrand factor (vWF), adrenomedullin, C type natriuretic peptide (CNP), NAD(P)H ox (p22phox), superoxide dismutase (SOD), leptin receptor, MTHFR, Æ-adducin, caveolin, t-PA and PAI-1.

The role of cardiac rehabilitation on endothelial dysfunction [67-72]. Exercise plays an essential role in CR programs. The beneficial effects of exercise on cardiovascular protection have been extensively 
shown; these include increasing exercise capacity, controlling cardiovascular risk factors, reducing inflammation, and reducing morbidity and mortality. Regular moderate-intensity exercise was reported to reduce all cardiovascular events. Exercise training is a well-established therapeutic intervention which has a number of benefits: modification of numerous traditional risk factors, enhancement of exercise tolerance, increase in myocardial and peripheral perfusion, and most importantly, reduction of morbidity and mortality in patients with CAD [6768]. However, the mechanisms underlying this positive impact are not fully understood. A series of studies [69-72] have recently evidenced the important role of exercise in mitigating endothelial dysfunction and vascular inflammation, and have generated a new set of potential explanations for the beneficial outcomes of regular exercise in CAD patients. Exercise training consistently improves nitric oxide bioavailability, increases the number of endothelial progenitor cells, and reduces the levels of inflammatory markers, namely proinflammatory cytokines and C-reactive protein. Nevertheless, the mechanisms by which exercise improves endothelial function in patients with coronary artery disease are not completely elucidated. Several mechanisms have been proposed to explain the positive effect of exercise on disease progression.

In conclusion, over the past two decades our understanding of the importance of measures of peripheral endothelial and vascular function has grown dramatically. Studies have provided unique insights into the pathophysiology of disease processes, the response to treatment and many have provided prognostic information that may be helpful in risk prediction. Peripheral measures of endothelial function are now established surrogate markers of vascular risk and have become important markers for clinical research.

Table 1. Methods for the assessment of endothelial funtion

\begin{tabular}{|c|c|c|}
\hline I.Imaging techniques & Invasive & Non-invasive \\
\hline a.Coronary arteries & $\begin{array}{l}\text { Quantitative coronary angiography } \\
\text { +pharmacological stimulation }\end{array}$ & Positron emission tomography \\
\hline & $\begin{array}{l}\text { Intracoronary Doppler ultrasound } \\
+ \text { pharmacological stimulation }\end{array}$ & Magnetic resonance imaging \\
\hline b.Peripheral arteries & $\begin{array}{l}\text { Measurement of FBF by strain-gauge } \\
\text { plethysmography after intra-arterial } \\
\text { vasoactive agent infusion }\end{array}$ & $\begin{array}{l}\text { High-resolution FMD ultrasound } \\
\text { Testing of the forearm vascular bed } \\
\text { by strain-gauge plethysmography } \\
\text { Evaluation of arterial parameters: } \\
\text { PWV, PCA, PAT }\end{array}$ \\
\hline c.Microcirculation & Skin biopsy & $\begin{array}{l}\text { Testing of microcirculation by laser } \\
\text { Doppler } \\
\text { RH-PAT }\end{array}$ \\
\hline $\begin{array}{l}\text { II. Determination of } \\
\text { biochemical } \\
\text { markers }\end{array}$ & \multicolumn{2}{|c|}{$\begin{array}{l}\text { Nitrites, asymmetric dimethylarginine, E-selectin, P-selectin, ICAM-1, } \\
\text { VCAM-1, tPA, PAI-1, vW factor, endothelial microparticles, progenitor } \\
\text { endothelial cells }\end{array}$} \\
\hline $\begin{array}{l}\text { III. Determination of } \\
\text { genetic markers }\end{array}$ & \multicolumn{2}{|c|}{$\begin{array}{l}\text { Angiotensin I converting enzyme (ACE), preproendothelin (ET)-1, } \\
\text { endothelin converting enzyme I (ECE-1), endothelin B receptor, eNOS, } \\
\text { NF-kB, ICAM-1, VCAM-1, E-selectin, von Willebrand factor (vWF), } \\
\text { adrenomedullin, C type natriuretic peptide (CNP), NAD(P)H ox } \\
\text { (p22phox), superoxide dismutase (SOD), leptin receptor, MTHFR, Æ- } \\
\text { adducin, caveolin, t-PA and PAI-1 }\end{array}$} \\
\hline
\end{tabular}


Table 2. Methods for the assessment of endothelial function [13]:

\begin{tabular}{|l|l|l|l|l|l|l|}
\hline Technique & $\begin{array}{l}\text { Non- } \\
\text { invasive }\end{array}$ & Repeatable & Reproducible & Reflecting biology & Reversible & Predictive \\
\hline $\begin{array}{l}\text { Cardiac } \\
\text { catheterization }\end{array}$ & - & - & $+/-$ & + & + & + \\
\hline Plethysmography & - & $+/-$ & $+/-$ & + & + & + \\
\hline FMD & + & + & $+/-$ & + & + & + \\
\hline PWA & + & + & $+/-$ & + & - & - \\
\hline PCA & + & + & $+/-$ & + & - & - \\
\hline PAT & + & + & $+/-$ & + & - & - \\
\hline
\end{tabular}

FMD=flow-mediated vasodilation, considered the non-invasive standard for endothelial function assessment; PWA=pulse wave analysis (modification of the augmentation index); PCA=pulse contour analysis (modification of the reflection index); PAT=pulse amplitude tonometry (modification of pulse amplitude)

Table 3. Advantages and disadvantages of endothelial function assessment techniques [15]

\begin{tabular}{|c|c|c|}
\hline Method & Advantages & Disadvantages \\
\hline $\begin{array}{l}\text { Quantitative } \\
\text { angiography }\end{array}$ & $\begin{array}{l}\text { Directly quantifies endothelial function in the } \\
\text { vascular bed of interest } \\
\text { Allows to establish the relationship between dose } \\
\text { and response to endothelial agonists and antagonists } \\
\text { Allows to examine basal endothelial function after } \\
\text { administration of NOS antagonists }\end{array}$ & $\begin{array}{l}\text { Invasive } \\
\text { Expensive } \\
\text { Risks related to coronary } \\
\text { catheterization: stroke, MI, } \\
\text { infection }\end{array}$ \\
\hline $\begin{array}{l}\text { Venous } \\
\text { plethysmography }\end{array}$ & $\begin{array}{l}\text { More accessible } \\
\text { Allows to establish the relationship between dose } \\
\text { and response to endothelial agonists and antagonists } \\
\text { Allows to examine basal endothelial function after } \\
\text { administration of NOS antagonists }\end{array}$ & $\begin{array}{l}\text { Invasive } \\
\text { Risks: median nerve injury, } \\
\text { infections, vascular injury }\end{array}$ \\
\hline $\begin{array}{l}\text { Vascular tonometry and } \\
\text { measurement of arterial } \\
\text { stiffness }\end{array}$ & $\begin{array}{l}\text { Non-invasive } \\
\text { Safe and rapid } \\
\text { Less operator-dependent than FMD } \\
\text { Can reflect basal endothelial function }\end{array}$ & $\begin{array}{l}\text { Influenced by structural vascular } \\
\text { aspects and less by the } \\
\text { endothelium }\end{array}$ \\
\hline $\begin{array}{l}\text { Flow-mediated vasodilation } \\
\text { (FMD) }\end{array}$ & $\begin{array}{l}\text { Non-invasive } \\
\text { Safe, rapid } \\
\text { Well correlated with coronary endothelial function } \\
\text { Blood flow is a physiological stimulus of } \\
\text { vasodilation, like agonists (AC) }\end{array}$ & $\begin{array}{l}\text { Low resolution influenced by the } \\
\text { vessel size } \\
\text { Inter-measurement variability } \\
\text { Operator dependence }\end{array}$ \\
\hline
\end{tabular}

\section{References}

1. Phillips SA, Andaku DK, Mendes RG, et al. Exploring Vascular Function Biomarkers: Implications for Rehabilitation. Brazilian Journal of Cardiovascular Surgery. 2017;32(2):125-135.

2. Humphreys RE1, Green DJ, Cable NT, Thijssen DH, Dawson EA.Low-flow mediated constriction: the yin to FMD's yang? Expert Rev Cardiovasc Ther. 2014;12(5):557-64.

3. Moncada S, Palmer RMJ, Higgs EA. Nitric oxide: physiology, pathophysiology and pharmacology. Pharmacol Rev 1991;43:109-42.

4. Radomski MW, Palmer RMJ, Moncada S. The antiaggregating properties of vascular endothelium: interactions between prostacyclin and oxid nitric. $\mathrm{Br}$ J Pharmacol 1987;92:639- 46.

5. Busse R, Edwards G, Feletou M, et al. EDHF : bringing the concepts together. Trends Pharmacol Sci. 2002;3:374-380.

6. Halcox JP, Narayanan S, Cramer-Joyce L, et al. Characterization of endothelium-derived hyperpolarizing factor in the human forearm microcirculation. Am J Physiol Heart Circ Physiol. 2001;280:H2470-H2477.

7. Ludmer PL, Selwyn AP, Shook TL, et al Paradoxical vasoconstriction induced by acetylcholine in atherosclerotic coronary arteries. N Engl J Med 1986, 315:1046-51.

8. Anderson TJ, Gerhard MD, Meredith IT, et al. Systemic nature of endothelial dysfunction in atherosclerosis. Am J Cardiol 1995;75:71-74. 
9. Verma S, Buchanan MR, Anderson TJ. Endothelial function testing as a biomarker of vascular disease. Circulation 2003;108:2054-59.

10. Tousoulis D, Antoniades C, Stefanides C. Evaluating endothelial function in humans:a guide to invasive and non-invasive techniques. Heart 2005;91:553-558.

11. Deanfield J, Donnald A, Ferri C, et al. Endothelial function and dysfunction. Part I:Methodological issues for assessment in the different vascular beds: A statement by the Working Group on Endothelin and Endothelial Factors of the European Society of Hypertension. J Hypertens 2005;23:7-17.

12. Brunner H, Cockroft JR, Deanfield J, et al. Endothelial function and dysfunction. Part II:Association with cardiovascular risk factors and disease. A statement by the Working Group on Endothelin and Endothelial Factors of the European Society of Hypertension. J Hypertens 2005;23:236246.

13. Deanfield JE, Halcox JP, Rabelink TJ. Endothelial function and dysfunction: testing and clinical relevance. Circulation. 2007 Mar 13;115(10):128595.

14. Hamburg NM, Keyes MJ, Larson MG, Vasan RS, Schnabel R, Pryde MM, et al. Crosssectional relations of digital vascular function to cardiovascular risk factors in the Framingham Heart Study. Circulation. 2008 May 13;117(19):2467-74.

15. Widlansky M.E., N. Gokce, Keaney J.F., et al. The Clinical Implications of Endothelial Dysfunction, J Am Coll Cardiol 2003;42:1149-60.

16. Tousoulis D., Davies G., Lefroy D.C. Variable coronary vasomotor responses to acetylcholine in patients with normal coronary arteriograms: evidence for localised endothelial dysfunction. Heart 1996; 75: 261- 266.

17. Doucette J.W.,Corl P.D., Payne H.M. Validation of Doppler guide wire for intravascular measurement of coronary artery flow velocity. Circulation 1992;85:1899- 1911.

18. Anderson A.J., Uehata A., Gerhard M.D. Close relation of endothelial function in the human coronary and peripheral circulations. J Am Coll Cardiol 1995; 26:1235-1241.

19. Lind L., Hall J., Johansson K. Evaluation of four different methods to measure endotheliumdependent vasodilation in the human peripheral circulation. Clin Sci 2002; 102:561-567.

20. Schindler T.H., Nitzsche E.U., Munzel T. et al. Coronary vasoregulation in patients with various risk factors in response to cold pressor testing: Contrasting myocardial blood flow responses to short- and long-term vitamin $\mathrm{C}$ administration. J Am Coll Cardiol 2003; 42: 814-822.
21. Green DJ, Dawson EA, Groenewoud HM, Jones H, Thijssen DH. Is flow-mediated dilation nitric oxide mediated? A meta-analysis. Hypertension. 2014;63(2):376-82.

22. Bellien J, Thuillez C, Joannides R.. Role of endothelium-derived hyperpolarizing factor in the regulation of radial artery basal diameter and endothelium-dependent dilatation in vivo. Clin Exp Pharmacol Physiol. 2008;35:494-497.

23. Celermajer DS, Sorensen KE, Gooch VM, Spiegelhalter DJ, Miller OI, Sullivan ID, Lloyd JK, Deanfield JE.Non-invasive detection of endothelial dysfunction in children and adults at risk of atherosclerosis. Lancet. 1992;340:1111-1115.

24. Corretti M.C., Anderson T.J., Benjamin J.E. et al. Guidelines for the ultrasound assessment of endothelial dependent flow madiated vasodilation of the brachial artery. A report of the international brachial artery reactivity task force. J Am Coll Cardiol 2002; 39: 257-265.

25. Cosio-Lima LM, Seip R, Thompson PD, Lagasse MA, Hodges TH. Intertester reliability of brachial artery flow-mediated vasodilation using upper and lower arm occlusion in healthy subjects. Vascular health and risk management. 2008;4(3):731-4.

26. Gori T, Dragoni S, Lisi M, Di Stolfo G, Sonnati S, Fineschi M, et al. Conduit artery constriction mediated by low flow a novel noninvasive method for the assessment of vascular function. J Am Coll Cardiol 2008;20;51(20):1953-8.

27. Donald AE, Halcox JP, Charakida M, Storry C, Wallace SM, Cole TJ, et al. Methodological approaches to optimize reproducibility and power in clinical studies of flow mediated dilation. Journal of the American College of Cardiology. 2008 May 20;51(20):1959-64.

28. Thijssen DH, Black MA, Pyke KE, et al. Assessment of flow-mediated dilation in humans: A methodological and physiological guideline. Am J Physiol Heart Circ Physiol. 2011;300:H2-H12.

29. Lekakis J, Abraham P, Balbarini A, et al. Methods for evaluating endothelial function: A position statement from the european society of cardiology working group on peripheral circulation. Eur J Cardiovasc Prev Rehabil.2011;18:775-78.

30. Anderson TJ, Phillips SA. Assessment and prognosis of peripheral artery measures of vascular function. Prog Cardiovasc Dis. 2015;57(5):497-509.

31. Frolow M, Drozdz A, Kowalewska A, Nizankowski $\mathrm{R}$, Chlopicki S.Comprehensive assessment of vascular health in patients; towards endotheliumguided therapy. Pharmacol Rep. 2015;67(4):786-92.

32. Vlachopoulos C, Xaplanteris P, Aboyans V, Brodmann M, Cífková R, Cosentino F, et al. The role of vascular biomarkers for primary and 
secondary prevention. A position paper from the European Society of Cardiology Working Group on peripheral circulation: Endorsed by the Association for Research into Arterial Structure and Physiology (ARTERY) Society. Atherosclerosis.

2015;241(2):507-32.

33. Gori T., Muxel S., Damaske A., Radmacher MC., Fasola F., Schaefer S. et al. Endothelial function assessment: flow-mediated dilation and constriction provide different and complementary information on the presence of coronary artery disease. Eur Heart J 2012; 33 (3): 363-371.

34. Humphreys RE, Green DJ, Cable NT, Thijssen DH, Dawson EA. Low-flow mediated constriction: the yin to FMD's yang? Expert Rev Cardiovasc Ther. 2014;12(5):557-64.

35. Schnabel RB, Wild PS, Schulz A, Zeller T, Sinning $\mathrm{CR}$, Wilde $\mathrm{S}$, et al. Multiple endothelial biomarkers and noninvasive vascular function in the general population: the Gutenberg Health Study. Hypertension. $2012 ; 60(2): 288-95$.

36. Yeboah J, Burke GL, Crouse JR, Herrington DM. Relationship between brachial flow mediated dilation and carotid intima-media thickness in an elderly cohort: the Cardiovascular Health Study. Atherosclerosis. 2008 Apr; 197(2):840-5.

37. Shimbo D, Grahame-Clarke C, Miyake Y, et al. The association between endothelial dysfunction and cardiovascular outcomes in a population-based multi-ethnic cohort. Atherosclerosis 2007;192:197203.

38. Schachinger V., Britten M.B., Zeiher A.M. Prognostic impact of coronary vasodilator dysfunction on adverse long-term outcome of coronary heart disease. Circulation 2000; 101: 18991906.

39. Suzuki T., Hirata K., Elkind M., et al. Metabolic syndrome, endothelial dysfunction, and risk of cardiovascular events: The Northern Manhattan Study (NOMAS). Am Heart J 2008;0:1-6.

40. Yeboah J, Crouse JR, Hsu FC, et al. Brachial flowmediated dilation predicts incident cardiovascular events in older adults: the Cardiovascular Health Study. Circulation 2007;115:2390-7.

41. Melikian N., Chowienczyk P., MacCarthy P.A., et al. Determinants of endothelial function in asymptomatic subjects with and without the metabolic syndrome. Atherosclerosis 2008;197: 375-382.

42. Uday M. Jadhav, N.N. Kadam. Non-Invasive Assessment of Arterial Stiffness by Pulse-Wave Velocity Correlates with Endothelial Dysfunction. Indian Heart J 2005; 57: 226-232.

43. Munakata M., Ito N., Nunokawa T., Yoshinaga K. Utility of automated brachial ankle pulse wave velocity measurements in hypertensive patients. Am J Hypertens 2003;16: 653-657.

44. Ramsey MW, Goodfellow J, Jones CJH, Luddington LA, et al. Endothelial control of arterial distensibility is impaired in chronic heart failure. Circulation 1995;92:3212-3219.

45. Kinlay S, Creager MA, Fukumoto M, et al. Endothelium-derived nitric oxide regulates arterial elasticity in human arteries in vivo. Hypertension 2001; 38:1049-1053.

46. Naka K., Tweddel A.C., Doshi SN, et al. Flowmediated changes in pulse wave velocity: a new clinical measure of endothelial function.European Heart Journal 2006; 27:302-307.

47. Hayward CS, Kraidly M, Webb CM, Collins P. Assessment of endothelial function using peripheral waveform analysis: a clinical application. Journal of the American College of Cardiology 2002;40(3):521-8.

48. Wilkinson IB, Hall IR, MacCallum H, Mackenzie IS, McEniery CM, van der Arend BJ, et al. Pulsewave analysis: clinical evaluation of a noninvasive, widely applicable method for assessing endothelial function. Arteriosclerosis, thrombosis, and vascular biology 2002;22(1):147-52.

49. Hamburg NM, Keyes MJ, Larson MG, Vasan RS, Schnabel R, Pryde MM, et al. Crosssectional relations of digital vascular function to cardiovascular risk factors in the Framingham Heart Study. Circulation 2008;117(19):2467-74.

50. Doucette J.W., Corl P.D., Payne H.M. Validation of Doppler guide wire for intravascular measurement of coronary artery flow velocity. Circulation 1992;85:1899- 1911.

51. Higashi Y., Sasaki S., Keigo N. Effect of angiotensin converting enzyme inhibitor imidapril on reactive hyperemia in patients with essential hypertension: relationship between treatment periods and resistance artery endothelial function. J Am Coll Cardiol 2001; 37: 863- 870.

52. Nabel E.G., Ganz P., Gordon J.B. Dilation of normal and constriction of atherosclerotic coronary arteries caused by the cold pressor test. Circulation 1988; 77: 43-52

53. Dhindsa M, Sommerlad SM, DeVan AE, Barnes JN, Sugawara J, Ley O, et al. Interrelationships among noninvasive measures of postischemic macro- and microvascular reactivity. J Appl Physiol 2008;105(2):427-32.

54. Nohria A, Gerhard-Herman M, Creager MA, et al. Role of nitric oxide in the regulation of digital puls volume amplitude in humans. J Appl Phisiol 2006;101:545-548.

55. Bonetti PO, Pumper GM, Higano ST, et al. Noninvazive identification of patients with early 
coronary atherosclerosis by assessment of digital reactive hyperemia. J Am Coll Cardiol $2004 ; 44$ :2137-2141.

56. Schier R., Marcus H.E., Mansur E. et al., Evaluation of digital thermal monitoring as a tool to assess perioperative vascular reactivity, J.Atheroscler.Thromb 2013;20:277-286.

57. Ahmadi N., Nabavi V., Nuguri V. et al., Low fingertip temperature rebound measured by digital thermal monitoring strongly correlates with the presence and extent of coronary artery disease diagnosed by 64 -slice multidetector computed tomography, Int. J. Cardiovasc Imaging.2009;25:725-738.

58. Millasseau S.C., Ritter J.M, Takazawa K., Chowienczyk P.J. Contour analysis of the photoplethysmographic pulse measured at the finger, J.Hypertens.2006;24:1449-1456.

59. Hamburg N.M., Palmisano J., Larson M.G. et al., Relation of brachial and digital measures of vascular function in the community: the Framingham heart study, Hypertension.2011;57:390-396.

60. Schnabel R.B., Schulz A., Wild P.S., et al., Noninvasive vascular function measurement in the community: cross-sectional relations and comparison of methods, Circ. Cardiovasc Imaging.2011;4:371-380.

61. Flammer A.J., Anderson T., Celermajer D.S., et al., The assessment of endothelial function: from research into clinical practice, Circulation. 2012;126:753-767.

62. Yousuf O., Mohanty B.D., Martin S.S., et al., Highsensitivity C-reactive protein and cardiovascular disease: a resolute belief or an elusive link? J.Am.Coll.Cardiol 2013;62:397-408.

63. Farcas AD, Rusu A, Stoia MA, et al. Plasma leptin, but not resistin, TNF-alpha and adiponectin, is associated with echocardiographic parameters of cardiac remodeling in patients with coronary artery disease. CYTOKINE, 2018; 103: 46-49.

64. Saplonţai-Pop A, Moţ A, Moldovan M, Oprean R, Silaghi-Dumitrescu R, Orăşan O, et al. Testing antiplatelet and antioxidant activity of the extract of seven varieties of Allium cepa L. Open Life Sciences, 2015; 10(1):89-98.

65. Mocan M, Anton F, Suciu S, et al. Multimarker Assessment of Diastolic Dysfunction in Metabolic Syndrome Patients. METABOLIC SYNDROME AND RELATED DISORDERS, 2017;15:507-514.

66. Cozma A, Sitar-Taut A, Orasan O, Procopciuc L, Farcas A, Stan A, Negrean V, Sampelean D, Pop D, Zdrenghea D, Fodor A. The Relationship Between eNOS (G894T) Gene Polymorphism and Arterial Stiffness in Patients with Metabolic Syndrome. REV.CHIM.(Bucharest), 2018; 69(9):2351:2356.
67. Peller M, Balsam P, Główczyńska R, Ossoliński K, Gilarowska A, Kołtowski Ł, et al. The impact of physical training on endothelial function in myocardial infarction survivors: pilot study. Kardiol Pol. 2016;74(5):439-46.

68. Da Silva CA, Ribeiro JP, Canto JC et al. Highintensity aerobic training improves endotheliumdependent vasodilation in patients with metabolic syndrome and type 2 diabetes mellitus. Diabetes Res Clin. Pract, 2012; 95: 237-245.

69. Cozma A, Sitar-Taut A, Dogaru G, Halloumi W, Schiau S, Oltean M. et al. Salbutamol-mediated effects on arterial parameters: a tool for subclinical atherosclerosis detection in patients with metabolic syndrome submitted to a cardiac rehabilitation program. Balneo Research Journal; 2018;9(2), 94100.

70. Cornelissen VA, Onkelinx S, Goetschalckx K et al. Exercise-based cardiac rehabilitation improves endothelial function assessed by flow-mediated dilation but not by pulse amplitude tonometry. Eur $\mathrm{J}$ Prev Cardiol. 2014; 21: 39-48.

71. M.J. Pearson, N.A. Smart. Effect of exercise training on endothelial function in heart failure patients: A systematic review meta-analysis. International Journal of Cardiology. 2017;231: 234-243.

72. Guo Y, Ledesma RA, Peng R, Liu Q, Xu D. The Beneficial Effects of Cardiac Rehabilitation on the Function and Levels of Endothelial Progenitor Cells. Heart, Lung And Circulation. 2017;26:10-17 